\title{
Electronic Portfolios in Higher Education: A Review of the Literature
}

\author{
Hwangji Lu
}

\section{ABSTRACT}

Electronic Portfolios have become a popular pedagogical approach on the tertiary educational landscape worldwide. In the United States, Association of American Colleges and Universities added this powerful pedagogical practice to its set of high-impact practices in 2016. Highimpact practices have the potential to generate transformative learning experiences and lead to significant impacts on students' academic achievements. Higher education has a responsibility to provide students with the means to support their professional learning and development as a continuous and lifelong process. Countless research studies have identified a number of benefits from utilizing ePortfolios in learning that are grounded in a variety of learning theories. As ePortfolios are gaining momentum as a preferred way to demonstrate students' learning and competencies, it is crucial for educators to fully understand the advantages of ePortfolios and guide students to produce quality and competitive ePortfolios.

Keywords: Electronic Portfolio, High-Impact Practices, Pedagogical Technology, Student-Centered.
Published Online: July 05, 2021

ISSN: $2736-4534$

DOI : $10.24018 /$ ejedu.2021.2.3.119

H. Lu*

The University of Arizona Global

Campus, Tucson, AZ, USA.

(e-mail: hwangji.lu@ ${ }^{@}$ uagc.edu)

*Corresponding Author

\section{INTRODUCTION}

Today's rapidly changing world demands higher education institutions to prepare students with various skills and competencies to take on challenges in the $21^{\text {st }}$ century. The most wanted skills and competencies among employers include communication, critical thinking, ethical decisionmaking, innovation, teamwork, technology, and problemsolving, in addition to the in-depth study of a particular discipline [1]-[3]. Employers highly value these cross-cutting skills and competencies that are critical to professional success, but they realize that college graduates may lack of some critical skills and competencies [1], [4]. In response to the needs of employers and changing environment, institutions of higher education are increasingly focusing on high-impact practices and implementing learning tools like electronic portfolios to prepare students with these desirable competencies [4].

This paper is organized as follows. It first describes what an electronic portfolio is. The next section is to examine the use of electronic portfolios in higher education institutions. The following section presents experiential learning theory, self-determination theory, and self-regulated learning as the foundational theories that espouse electronic portfolios. One section is dedicated to the review of past research studies on electronic portfolios in higher education contexts. Finally, the author concludes this paper by offering her final thoughts in electronic portfolios.

\section{What IS AN ELECTRONIC PORTFOLIO?}

The portfolio is one of the useful tools to evaluate student's learning [5]. It is also a detailed description of learning that has occurred [6]. With the burgeoning of informational technology in the early 1990s, electronic portfolios, or ePortfolios, emerged and enabled learners to move beyond binder and paper portfolios to demonstrate their capabilities in digital form [7]. The ePortfolio can be defined as a digitalized collection and presentation of a student's experiences, efforts, progress, and academic achievements over a period of time [1], [6], [7]. ePortfolio provides a platform for learners to articulate how their educational experience at the educational institution prepares them for future academic and career goals by demonstrating visibly and audibly what they have learned throughout their academic learning journey [8].

ePortfolio allows learners to be more deliberate in incorporating their academic, personal, and professional goals with their learning [1]. The ePortfolio houses students' authentic and reflective evidence that also reflects upon students' interactive and individual characteristics [5]. Evidence representing student's learning can be digital artifacts, written reflections on both formal and informal learning experiences, collaborative assignments, learning achievements, research activities, and community engagement [2], [3], [6], [7]. Moore contended that evidence could also be personal and professional creativity and performance, projects that prepared for class or 
extracurricular activities, community involvements, and extracurricular or co-curricular activities to showcase leadership or other skills [5].

ePortfolio is defined by Kuh, O'Donnell, and Schneider [9] as "a powerful pedagogical approach that requires meaningful student reflection and deepens learning while making achievement visible - to students themselves, to their peers and faculty, and to external audiences" (p. 10). Alex and Paraskeva [10] described the ePortfolio as a digital collection of information where students create, collect, evaluate, interpret, reflect upon, and select their own work for targeting specific audiences and demonstrating evidence for lifelong learning and skills in an academic and professional context. ePortfolio that represents a compelling digital resume is an effective marketing tool to attract prospective employers and other stakeholders for commenting and feedback [5].

\section{The Use of EPORTFOlio IN Higher EdUCATION}

Over the past decade, eportfolios have been extensively used in higher education worldwide [8]. As the prominent teaching and learning method, ePortfolios have been used in more than half of higher education institutions in the United States [5], [11], [12]. Based upon the findings from numerous research studies on the efficacy of ePortfolios, the Association of American Colleges and Universities in the United States strongly endorsed ePortfolio and added this powerful pedagogical practice to its set of high-impact practices in 2016 [7]. High-impact practices and their fundamental components were originally established throughout multiple data analyses from the National Survey of Student Engagement (NSSE) in 2007, which are an evidently robust set of ten interventions to advance student success [9]. Examples of these ten high-impact practices are internships, learning community, study abroad, and studentfaculty research [13].

High-impact practices are also known as engaging educational practices because students who participated in any of the high-impact practices demonstrated higher commitment and more desirable learning outcomes when comparing to those students who did not participate in any experience in high-impact practice. [9], [13]. After examining a plethora of empirical evidence, Kuh [9] recommended ePortfolio to be the eleventh high-impact practice in 2017. High-impact practices are indispensable for helping educational institutions ensure access, equity, and quality in education [9], [13]. ePortfolios are widespread in many disciplines, such as accounting, business studies, criminal justice, engineering, fine arts, language, musical education, nonprofit studies, nursing, occupational therapy, pre-service teacher education, public health, science, social work, and vocational higher education training [2], [4], [6], [8], [12].

\section{THEORETICAL FOUNDATIONS}

Literature has documented various principles and theories in relation to the development and use of ePortfolios as a tool for enhancing curriculum, instruction, and assessment. In this paper, three important theories will be discussed thoroughly. They are David Kolb's [14] experiential learning theory,
Edward Deci, and Richard Ryan's [15] self-determination theory, and Barry Zimmerman's [16] self-regulated learning.

\section{A. Experiential Learning Theory}

Experiential learning can be portrayed as a pedagogical practice engaging students' active participation in their own learning journey [7], [17]. Kolb's experiential learning theory is represented by a four-stage cycle of learning and has a more holistic approach [17]. These four individual learning styles include concrete experience, reflective observation, abstract conceptualization, and active experimentation. These four stages are an integrated learning process, and each stage is mutually supportive of and feeds into the next [17], [19]. This four-stage cycle of learning also explains how personal experience is translated through reflection into concepts, which are used as guides for the new experiences [18]. The first and second stages, concrete experience, and abstract conceptualization, are two methods of comprehending experience, while the third and fourth stages, reflective observation and active experimentation, are two means of transforming experience [14]. Both grasping and transforming experience result in knowledge. Kolb [14] defined this type of learning as "a process whereby knowledge is created through the transformation of experience" (p. 38). The experiential learning theory advocated by Kolb asserts that experiences, cognition, emotions, and environmental factors all impact the learning process [17], [18].

The experiential learning theory is relevant and applicable to the construction of ePortfolio because knowledge is acquired through active experience and created through the transformation of personal experience [7], [17], [18]. Effective learning occurs when the learners progress through one cycle of all four stages of the learning model within a logical sequence [19]. In the very beginning, students collect evidence from their prior studying occurrences to build an ePortfolio [20]. Concrete experience supplies information that serves as a source for reflection. In the stage of reflective observation, students appraise their ePortfolios as well as contemplate and examine the progress that they have accomplished over time [18], [20]. Students' learning in this stage focuses on understanding the meaning of ideas and situations by carefully observing and describing them [20]. When students construct their ePortfolio and reason their learning, they perceive their weaknesses and strengths in the evidence that they have produced and displayed in their ePortfolios [18]. From reflection, students are capable of assimilating the information to form abstract concepts.

In the stage of abstract concept, students use concepts, ideas, and logic to form generalizations and theories about their learning experience [14], [17]. They create a time-bound outline of learning encounters in their ePortfolio and expand higher-order critical-thinking and problem-solving skills [20]. Based upon the abstract concepts, students will formulate new hypotheses and theories in a future situation and actively tested the newly formed theories [14]. In the stage of active experimentation, students generate and upload an assortment of artifacts and converse with their peers or instructor [18], [20]. They actively influence others by testing and applying the resulting concepts in new situations. Furthermore, students acquire new experiences from what 
they have experimented with, which initiates the beginning of another four-stage cycle of learning [14]. Overall, Kolb's experiential learning theory suggested that no experience can become a learning experience without reflection, analysis, and evaluation.

Based on the four-stage learning cycle, Kolb's also developed a learning styles inventory because each individual naturally has a preferred learning style different from others. Several factors can impact a person's preferred style, for example, educational backgrounds, social surroundings, and the rudimentary cognitive makeup of the individual [14]. These four prevailing learning styles are assimilating, converging, accommodating, and diverging, and Kolb believed that learning styles determine how individuals learn [17]. Assimilators take a concise, logical approach and prefer sound logical theories. Since, to assimilators, concepts are more important than people, they are less interested in people and more focused on abstract concepts and ideas [14]. Convergers favor technical tasks and problems, but they are less related to human beings and interpersonal aspects [14], [17]. They prefer to have practical applications of concepts and theories and like to use their learning to find solutions to practical issues. Divergers are disposed to look at concrete situations from different perspectives [14]. They are sensitive and tend to watch rather than do. Despite learning style differences among individuals, ePortfolio represents value for learners with varying learning styles because concepts, theories, information, observations, and experience are all appreciated components that can contribute to creating and developing of an ePortfolio [17].

\section{B. Self-Determination Theory}

Self-determination theory was first proposed by psychologists Richard Ryan and Edward Deci's 1985 book, Self-Determination and Intrinsic Motivation in Human Behavior. They suggested that people are more likely to be driven by the inherent motivational propensities to grow, learn, gain fulfillment, and connect with others [15], [21]. Deci and Ryan [22] argued that motivation stimulates people's actions to grow and change because their psychological needs are satisfied - specifically autonomy, competence, and relatedness. However, psychological growth does not happen automatically [15], [22]. It requires continual supports to foster the inner resources for the healthy development of individuals. When these psychological demands are fulfilled, wellbeing and self-motivation are further developed [22].

In Self-Determination Theory, Deci, and Ryan [15] differentiated between two different types of motivation, intrinsic motivation, and extrinsic motivation, based on the different motives or purposes that lead to action. Intrinsic motivation does not depend on external rewards; rather, it is seen as the inherent satisfaction of activity itself; the completion of the activity provokes the internal interest and brings joy [22]. The concept of intrinsic motivation plays a crucial role in self-determination theory. Intrinsic motivation is more than likely accountable for human learning across the life span since self-determination theory focuses primarily on internal sources of motivation, for instance, a need to gain knowledge or independence [15], [21]. Additionally, Ryan and Deci [22] believed that offering positive feedback and inspiration on a person's performance for a specific task can boost intrinsic motivation. The encouraging feedback prompts people to feel more competent about themselves and feeling competent is one of the important forces for personal growth. As students develop intrinsic motivation for creating an ePortfolio, they are granted more autonomy over the look, layout, and content of their ePortfolio. Providing students with the ability to personalize their ePortfolio is directly related to their intrinsic motivation and active engagement [11].

In contrast, extrinsic motivation refers to those activities driven by the instrumental value that is undertaken in order to attain different outcomes other than enjoyment or internal contentment [22]. Ryan and Deci [23] further divided extrinsic motivation into four different types in relation to their relative autonomy. The first type, extrinsic regulation, is the least autonomous form of extrinsic motivation, in which one is controlled by an external demand or extrinsic reward contingency [22], [23]. The second type is called introjected regulation [23]. This is the kind of behavior where people feel as though they have little autonomy due to feeling pressured to engage in an activity. The third style is called identified regulation, which has a more autonomously driven form of extrinsic motivation [23]. People perceive the personal importance of behavior as being tied to career goals and accept its regulation as their own [21], [22]. The fourth and last style, integrated regulation, is the most autonomous form of extrinsic motivation [23]. It is achieved when regulations are fully assimilated to one's personal values, beliefs, and needs through self-examination [22], [23]. One's actions have become self-determined when one internalizes the reasons for an action or behavior and assimilates them to the self [23]. However, those reasons are still classified as extrinsic because the goals or purposes that one is trying to achieve are for reasons extrinsic to the self - not the inherent enjoyment or internal interest in the activity [21].

Although extrinsic and intrinsic motivation are often depicted as distinct and separate, people are rarely driven to act by a single source of motivation [23]. Instead, the multiple sources of motivation drive people to pursue their goals. When students create and develop their ePortfolio, for example, they are extrinsically motivated by a desire to earn a better grade, gain approval from others, or obtain a job offer from an employer as well as intrinsically motivated by the interest, enjoyment, self-improvement, and inherent satisfaction that they achieve from the activity [22], [23].

\section{Self-Regulated Learning}

Self-regulated learning (SRL) is a conceptual framework to appreciate the cognitive, emotional, and motivational aspects of learning [24]. Self-regulated learning enables students to be proactive in their efforts to learn, understand their strengths and weaknesses, establish individual goals, define strategies to achieve their goals, monitor their progress, and improve the learning methods [16], [25]. Selfregulated students incline to possess skills of setting goals, planning strategies, self-reinforcement, monitoring performance, managing time, evaluating results, and adapting to future, better study methods [26]. In this type of learning, self-regulated learners are aware of their knowledge and skills, actively engage in their learning, and become masters 
of their learning processes [25], [26]. Self-regulated learning is the self-directive process through which learners transform their mental and physical abilities into task-related skills in various areas [25]. Self-regulation learning is not an individualized form of learning. Indeed, it includes selfcoordinated collective forms of learning that individual outcomes are accomplished through the actions of others [16], [24].

Zimmerman's model of self-regulated learning [16] expressed the learning process in terms of three cyclical phases: forethought, performance, and self-reflection, in which students cognitively, motivationally, and behaviorally engage in learning. In the forethought phase, students plan to learn by analyzing the tasks, setting goals, and initiating learning strategies [24], which involves students' selfmotivational beliefs as well as task analysis, goal setting, and planning skills [26]. The second phase of performance seeks to optimize learning efforts and comprises learning strategies, self-instruction, and self-recording processes [16], [27]. Students monitor their progress and utilize a number of selfcontrol strategies to keep themselves cognitively engaged and motivated. The final self-reflection phase involves selfjudgment and self-reactions [16]. Students evaluate how they have performed the tasks, which could contribute to their success or failure in learning [26]. Either positive or negative attribution will affect how students continue the tasks regarding further efforts to learn. Students plan for the tasks through these cyclical phases, monitor their performance, and then reflect on the outcome metacognitively, motivationally, and behaviorally [16]. The cycle then repeats when students use their reflection to adjust the learning process and prepare for the following tasks. Self-regulation of learning is a key factor in creating an ePortfolio. While building their ePortfolio, students go through processes of planning, synthesis, presentation, discussion, and reflection, which resonate with the processes of self-regulated learning [26].

\section{EMPIRICAL EVIDENCE}

In the past few decades, researchers around the world have engaged in ePortfolio research to empirically assess the benefits of ePortfolios in higher education contexts. In particular, C2L, a FIPSE-funded project organized by the Making Connections National Resource Center of LaGuardia Community College (CUNY), has coordinated 24 higher educational institutions across the United States with established ePortfolio projects into a national community of practice [9], [28]. They have sought to conduct analyses on the efficacy of ePortfolios with a wide range of purposes and settings such as assessment, pedagogy, and professional development. The findings from some $\mathrm{C} 2 \mathrm{~L}$ research projects suggested that the ePortfolio pedagogical tool can help students engage deeply in their learning process, sustain student success, generate meaningful outcomes assessments, and bring greater coherence, connectedness, and meaning for student's learning journey [28]. This network has guided higher educational institutions in developing effective ePortfolio projects and providing sound evidence, best practices, and pedagogical strategies that can enrich student learning [28].
To examine the correlation between the use of ePortfolios and improved student performance in retention of knowledge and content mastery, Fuller [3] undertook a quasiexperimental, explanatory, mixed-methods approach in an Introduction to Biology course at a small community college in New York City. The results confirmed that the use of ePortfolios correlated with increased retention and improved learning. Moreover, the findings also indicated that when ePortfolios were used for periodic formative assessments, they are likely to invigorate student's responses to feedback and, additionally, improve the quality of student work, which results in increased student engagement. Furthermore, improved grades and higher retention rates were also observed in this study. Overall, the findings suggested that ePortfolio as an effective, promising intervention can increase student engagement, improve student performance, and raise the completion rate for nonmajors students in an introductory biology course.

In a qualitative study, Andrade [1] ascertained business students' experience in relation to their involvement in ePortfolios and teamwork in the organizational behavior class taught at a university in Utah, USA. The results revealed that ePortfolios could transform learning and reap significant gains in learning, as evidenced in the ePortfolios created by the teams. Participants were able to apply learned knowledge and concepts through study and interaction. Participants were able to improve their ability to communicate, resolve conflict, and lead or work in teams by applying the concepts and theories taught in the course. ePortfolios also allow them to increase their understanding, tolerance, and appreciation of their teammates' personalities, backgrounds, preferences, and ideas.

To evaluate the implementation and usage of ePortfolio in the Bachelor of Nursing program at a university in Dunedin, New Zealand, Collins, and O'Brien [2] conducted exploratory, mixed-methods research to include surveys and focus groups. Their findings showed that students viewed enhanced learning, reduced costs, increased privacy, and the capability of sharing with future employers as perceived usefulness. There are several benefits identified by those students who used ePortfolio to present their clinical work. The benefits include the ability to support academic quality, the capacity to share evidence of learning with faculty and future employers as well as improved learning and a sense of gratification through reflection and timely feedback.

Numerous empirical studies on ePortfolios demonstrate that the creation and development of ePortfolios can facilitate the active process of retrieving and applying knowledge and enhance learners' self-awareness, higher-order critical thinking, and problem-solving skills. One of such studies was carried out at a college in New York, United States. Bowman, Lowe, and Sabourin [29] conducted a qualitative case study design to include several sections of two required courses in the first-year program. They compared the impact of using ePortfolios and traditional portfolios to determine any pedagogical benefits, such as metacognition skills, offered from ePortfolios. As the findings uncovered, even though both types of portfolios have positive impacts on students' learning in relation to "connections to the course," study participants concluded that an ePortfolio displays higher 
levels of metacognition in relation to "connections to learning" and "connections to career or personal goals."

Payne, Paredes, and Cross explored how students who majored in cybersecurity, criminal justice, and leadership viewed ePortfolios and their recommendations to others developing ePortfolios in a qualitative study [8]. Among 145 respondents, 77 reported they had created an ePortfolio for their course or program before. Some respondents indicated ePortfolio is a process because of the dynamic nature of ePortfolio. Other respondents viewed ePortfolio as a product since they learned about the value of ePortfolio as a showcase tool. Owing to their review regarding ePortfolio as a showcase tool, those respondents felt strongly about recommending others to create their ePortfolio as an ePortfolio creates a professional identity for students.

\section{CONCLUSION}

The objective of this article is to perform an overview on a high-impact pedagogical tool, ePortfolio. In the past few decades, ePortfolios have gradually been adopted in higher education globally. As ePortfolios have become more widespread, researchers in education have begun to define, theorize, develop pedagogy, and conduct empirical research to examine ePortfolios from various aspects. Through appraising the theoretical foundations upheld ePortfolios and previous empirical research studies concerning ePortfolio in higher education, a greater understanding of the practices, benefits, and pedagogies of ePortfolios would have been achieved. ePortfolio is considered as a record of documentations articulating student's progress, skills, competencies, experiences, and achievements over time. In addition, ePortfolios function as an expanded CV to present the best work of a student to prospective employers or other stakeholders. There has been growing evidence of the ePortfolio's impacts on student's learning in the higher education context. It is critically important for educators and institutions to consider that the integration of this pedagogical approach should be thoughtfully woven throughout the curricula in a program, capturing the entire students' learning experience during the time of pursuing the degree.

\section{REFERENCES}

[1] M. S. Andrade, "ePortfolios and online learning: Applying concepts of organizational behavior," International Journal of E-learning and Distance Education, vol. 34, no. 1, pp. 1-15, 2019.

[2] E. Collins, and R. O'Brien, "Highly structured ePortfolio platform for bachelor of nursing students: Lessons learned in implementation,' International Journal of ePortfolio, vol. 8, no. 1, pp. 43-55, 2018.

[3] K. Fuller, "Beyond reflection: Using ePortfolios for formative assessment to improve student engagement in non-majors introductory science," The American Biology Teacher, vol. 79, no. 6, pp. 442-449, 2017.

[4] M. Ciesielkiewicz, C. F. Bonilla, and C. O. López de Ayala, "The potential of the ePortfolios as a recruitment tool: From the perspective of HR directors," International Journal of Interactive Mobile Technologies, vol. 14, no. 3, pp. 109-120, 2020.

[5] K. Moore, "Tools and tips for helping students create e-portfolios," Computers in Libraries, vol. 39, no. 8, pp. 32-37, 2019.

[6] L. Cordie, J. Sailors, B. Barlow, and J. S. Kush. "Constructing a professional identity: Connecting college and career through ePortfolios," International Journal of ePortfolio, vol. 9, no. 1, pp. 1727. 2019 .

[7] D. Farrelly, and D. Kaplin, "Using student feedback to inform change within a community college teacher education program's ePortfolio initiative," The Community College Enterprise, vol. 25, no. 2, pp. 9-38 2019.

[8] B. K. Payne, T. Paredes, and B. Cross, "Student perceptions about the production of electronic portfolios: Technology, process, and showcase insights," Education, vol. 141, no. 2, pp. 67-78, 2020.

[9] G. D. Kuh, K. O'Donnell, and C. G. Schneider, "HIPs at ten," Change: The Magazine of Higher Learning, vol. 49, no. 5, pp. 8-16, 2017. https://doi.org/10.1080/00091383.2017.1366805.

[10] A. Alexiou, and F. Paraskeva, "Implementing a self-regulated oriented ePortfolio: The design of an affective goal-setting plugin [Paper presentation]," 2014 IEEE 14th International Conference on Advanced Learning Technologies, Athens, Greece, pp. 474-476, July 7-10, 2014. doi: 10.1109/ICALT.2014.140.

[11] S. M. Fallowfield, M. Urtel, R. Swinford, L. Angermeier, and A. S. Plopper, "A case study in ePortfolio implementation: A departmentwide perspective," International Journal of ePortfolio, vol. 9, no. 2, pp. 111-118, 2019

[12] T. M. Freeman, "The case for integrating ePortfolio pedagogy into nonprofit and philanthropic studies,". Journal of Nonprofit Education \& Leadership, vol. 10, no. 3, pp. 231-245, 2020.

[13] R. Martin, “Taking student success to scale," Change: The Magazine of Higher Learning, vol. 49, no. 1, pp. 38-47, 2017. doi: 10.1080/00091383.2017.1265391.

[14] D. A. Kolb, Experiential Learning: Experience as the Source of Learning and Development (vol. 1), Englewood Cliffs, NJ: PrenticeHall., 1984.

[15] E. Deci, and R. M. Ryan, Intrinsic Motivation and Self-Determination in Human Behavior, London: Springer, 1985, pp. 11-40.

[16] B. J. Zimmerman, "Becoming a self-regulated learner: an overview," Theory Into Practice, vol. 41, no. 2, pp. 64-70, 2002. https://doi.org/10.1207/s15430421tip4102_2.

[17] J. Green, A. Wyllie, and D. Jackson, "Electronic portfolios in nursing education: a review of the literature," Nurse Education in Practice, vol 14, no. 1, pp. 4-8, 2014. doi: 10.1016/j.nepr.2013.08.011.

[18] M. E. Douglas, S. Peecksen, J. Rogers, and M. Simmons, M. "College students' motivation and confidence for ePortfolio use," International Journal of ePortfolio, vol. 9, no. 1, pp. 1-16, 2019.

[19] N. Yeo, and J. Rowley, "Putting on a show' non-placement will in the performing arts: Documenting professional rehearsal and performance using ePortfolio reflections," Journal of University Teaching \& Learning Practice, vol. 17, no. 4, preceding pp 1-17, 2020.

[20] T. de Jager, "Impact of ePortfolios on science student-teachers' reflective metacognitive learning and the development of higher-order thinking skills," Journal of University Teaching and Learning Practice, vol. 16, no. 3, Article 3, 2019.

[21] A. M. Korhonen, S. Ruhalahti, M. Lakkala, and M. Veermans, "Vocational student teachers' self-reported experiences in creating ePortfolios," International Journal for Research in Vocational Education and Training, vol. 7, no. 3, pp. 278-301, 2020 https://doi.org/10.13152/IJRVET.7.3.2.

[22] R. M. Ryan, and E. L. Deci, "Intrinsic and extrinsic motivation from a self-determination theory perspective: Definitions, theory, practices, and future directions," Contemporary Educational Psychology, vol. 61, April 2020. https://doi.org/10.1016/j.cedpsych.2020.101860.

[23] R. M. Ryan, and E. L. Deci, "Self-determination theory and the facilitation of intrinsic motivation, social development, and wellbeing," American Psychologists, vol. 55, no.1, pp. 68-78, 2000. https://doi.org/10.1037/0003- 066X.55.1.68.

[24] E. Panadero, "A review of self-regulated learning: Six models and four directions for research," Frontiers in Psychology, 2017. https://doi.org/10.3389/fpsyg.2017.00422.

[25] G. Tur, S. Urbina, and D. Forteza, "Rubric-based formative assessment in process ePortfolio: Towards self-regulated learning," Digital Education Review, vol. 35, pp. 18-35, 2019.

[26] L. T. Nguyen, and M. Ideda, "ePortfolio system design based on ontological model of self-regulated learning," 2014 IIAI 3rd International Conference on Advanced Applied Informatics, Kitakyushu, 2014, pp. 301-306, doi: 10.1109/IIAI-AAI.2014.69.

[27] B. J. Zimmerman, "From cognitive modeling to self-regulation: a social cognitive career path." Journal of Educational Psychology, vol. 48, pp. 135-147, 2013. doi: 10.1080/00461520.2013.794676.

[28] B. Eynon, and L. Gambino, Catalyst for learning: ePortfolio-based outcomes assessment. Urbana, IL: University of Illinois and Indiana University, National Institute for Learning Outcomes Assessment (NILOA), April 2014. https://www.learningoutcomesassessment.org/wpcontent/uploads/2019/08/Viewpoint-EynonGambino.pdf.

[29] J. Bowman, B. J. Lowe, and K. Sabourin, "The use of ePorfolios to support metacognitive practice in a first-year writing program," International Journal of ePortfolio, vol. 6, no.1, pp. 1-22, 2016. 
Hwangij Lu holds two master's degrees in nutrition from North Dakota State University in Fargo ND and health services administration from Center Michigan University in Mount Pleasant MI of the United States. She earned her $\mathrm{PhD}$ in management with a specialization in leadership and organizational change from Walden University in Minneapolis, MN.

Currently, she is a Remote Associate Professor in the master's program of health care administration at the University of Arizona Global Campus (UAGC). Apart from UAGC, she has taught online courses at a number of universities since 2006. Prior to this post, she had over 20 years of professional experiences in various industries - inside and outside the health care arena. Her research interests include leadership development, student engagement, course evaluations, and using innovated technology in the online education.

Dr. Lu is a member of professional societies such as Academy of Management, Multimedia Educational Resource for Learning and Online Teaching, and International Economics Development and Research Center. She is also an advisory member for the International Society for Engineering Research and Development and the Institute of Research Engineers and Scientists. Dr. Lu was named as the recipients of Provost's Circle Award at a couple of universities in 2009 and 2010. She won the Best Paper Award from IC4E 2016 held in St. Petersburg, Russia. Dr. Lu was awarded as an Outstanding Reviewer by the Academy of Management Health Care Management Division in 2008 and 2018. In 2021, she received the Distinguished Scholar Award from European Journal of Scientific Research. 